\title{
Os novos Bezerros de Ouro: estaríamos vivendo um surto iconoclasta?
}

\section{Clara Habib de Salles Abreu'}

Resumo: Além de funcionar como um ensaio que visa questionar se estamos testemunhando um novo período iconoclasta, este trabalho tem como objetivo fazer uma introdução ao presente dossiê temático.

Palavras-chave: Iconoclastia. Bezerro de ouro. Monumentos públicos. Lugar de memória.

\section{The New Golden Calves: Are We Experiencing an Iconoclastic Outbreak?}

\begin{abstract}
Besides questioning whether we are currently witnessing a new iconoclastic period, this essay is an introduction to this special issue of our journal.
\end{abstract}

Keywords: Iconoclasm. Golden calf. Monuments. Places of memory.

I Doutora em Artes Visuais na linha de pesquisa teoria e história da arte pelo Programa de Pós-Graduação da Universidade do Estado do Rio de Janeiro (PPGARTES/UERJ). Professora substituta do Departamento de Teoria e História da Arte do Instituto de Artes da Universidade do Estado do Rio de Janeiro (DTHA/IART/UERJ). Rua São Francisco Xavier, Maracanã - $20550-010$ - Rio de Janeiro - RJ. E-mail: clara.habib.hca@gmail.com ORCID: https://orcid.org/0000-0003-0576-0968. Lattes iD: http://lattes.cnpq. br/5169278435589514. Rio de Janeiro, Brasil. 
Segundo o Livro do Êxodo, enquanto Moisés estava no Monte Sinai recebendo as Tábuas da Lei, seu povo, impaciente com sua demora em selar a aliança com Deus, fazia justamente o que Ihe fora proibido: construía um novo ídolo para adorar, um bezerro de ouro.

Não terás outros deuses diante de mim.

Não farás para ti imagem esculpida de nada que se assemelhe ao que existe lá em cima nos céus, ou embaixo na terra, ou nas águas que estão debaixo da terra.

Não te prostrarás diante desses deuses e não os servirás, porque eu, lahweh teu Deus, sou um Deus ciumento, que puno a iniquidade dos pais sobre os filhos até a terceira e a quarta geração dos que me odeiam, mas que também ajo com amor até a milésima geração para com aqueles que me amam e guardam os meus mandamentos. ${ }^{1}$

Deus, em sua onisciência, alertou Moisés da corrupção de seu povo e prometeu castigá-los com a morte. Moisés, entretanto, suplicou a misericórdia divina, desceu do monte e destruiu o bezerro de ouro, ensinando uma lição aos idólatras. Tal passagem foi utilizada ao longo da história para justificar o princípio do aniconismo presente inicialmente nas três religiões abraâmicas, ou seja, a interdição da representação do divino através da materialidade da imagem.

A partir da "Nova Aliança", a Encarnação de Cristo como "imagem e semeIhança" do Deus invisível autorizou, no contexto do Cristianismo, a produção de imagens materiais e sua veneração proibidas no Êxodo. A política do Cristianismo no que diz respeito ao culto das imagens, entretanto, foi frequentemente atravessada pela interdição veterotestamentária, que era resgatada a cada vez que "veneração" e "adoração" se confundiam, e com frequência serviu como fundamentação para ataques iconoclastas. Assim, em diferentes momentos, a história testemunhou a destruição de imagens/ ídolos cristãos fundamentada no princípio do aniconismo.

Apesar dos processos de construção e destruição de imagens religiosas nunca terem cessado de existir, a crescente laicização da sociedade a partir do lluminismo acarretou um fenômeno de substituição dos ídolos cristãos por ídolos cívicos e políticos habitualmente cultuados em praça pública. Assim, a história também testemunhou um surto de construção de estátuas 
e monumentos públicos laicos de caráter celebrativo e mnemônico, uma verdadeira "estátuomania" dedicada a cultuar figuras representativas das monarquias, repúblicas, forças armadas etc. Até hoje os espaços públicos são tomados pela materialidade de um culto a espécies de "espíritos" que nas Américas e na África, muitas vezes, encarnam em pedra e metal, a forma do "espírito-cão, espírito-de-porco, espírito-canalha"2 representante da empresa colonialista.

Atualmente assistimos o crescimento de ações de destruição de monumentos (ou de interferências artísticas/ideológicas neles) nos quais as barbáries da empresa colonialista vêm à tona como a maior motivação ideológica. No dia 07 de julho de 2020 membros do grupo "Black Lives Matter" derrubaram a estátua do traficante de pessoas escravizadas Edward Colston na cidade de Bristol durante uma manifestação em repúdio ao assassinato brutal de George Floyd por um policial estadunidense. O intensamente noticiado ataque iconoclasta acabou levando para a opinião pública ferrenhos debates sobre "vandalismo" e preservação do patrimônio que já tomavam forma nos EUA com o questionamento das estátuas dos confederados e na América Latina com as estátuas de Colombo. A opinião pública se viu dividida entre aqueles que eram a favor da destruição de monumentos hoje considerados inadequados, e outros que consideraram tais atos apenas como ações de vandalismo performadas por grupos extremistas. Uma terceira parcela da opinião pública ainda buscava encontrar uma "boa medida" entre os dois extremos, e propunha que tais estátuas e monumentos fossem transferidos para museus ou outras instituições tendo assim sua função passando de celebrativa para pedagógica. Deste modo, a materialidade do patrimônio público seria preservada e utilizada para ensinar uma história que não deveria jamais ser repetida. Sabemos, entretanto, que tais manobras não são facilmente executadas. $O$ destino da estátua de Edward Colston, inclusive, já estava sob lenta negociação entre representantes do movimento negro local e a prefeitura da cidade. Diante de um estopim tão sério como o assassinato de um homem inocente, não houve outra solução senão o simbólico ato de destruição de um monumento em homenagem a um escravista.

Tais ações e debates também vêm ocupando as mãos e mentes dos brasileiros. No dia 24 de julho, uma estátua em homenagem ao bandeirante 
Borba Gato foi incendiada na cidade de São Paulo e na madrugada do dia 24 de agosto foi a vez da estátua de Pedro Álvares Cabral no Rio de Janeiro, danificada no contexto das manifestações contra o Marco Temporal que implica mudanças nas regras de demarcação das terras indígenas. Ambas as destruições se inserem em um debate decolonial que pretende dar voz a minorias que, por muitas vezes, somente conseguem ser ouvidas através de ações radicais como tais atos de caráter iconoclasta.

A lógica colonialista construiu seus lugares artificiais de memória como uma estratégia para escrever uma história através de suas narrativas, pela perspectiva do colonizador. Era como se o "Novo Mundo" tivesse sido, de fato, uma terra virgem de memórias, aberta à exploração, uma tela em branco para pintar uma nova história, a história do vencedor. Assim, as memórias dos povos originários americanos e dos povos escravizados africanos passou por constantes tentativas de apagamento. Eles foram dizimados e convertidos, destituídos da completude de suas práticas e tradições e quando, por fim, sua memória coletiva foi fragilizada, eles sequer puderam construir seus lugares de memória. Pierre Nora observa que a demanda pela construção de lugares de memória é evidente em situações na qual a memória coletiva já não é mais viva e ativa naquela sociedade.

A curiosidade pelos lugares onde a memória se cristaliza e se refugia está ligada a este momento particular da nossa história. Momento de articulação onde a consciência da ruptura com o passado se confunde com o sentimento de uma memória esfacelada, mas onde o esfacelamento ainda desperta memória suficiente para que se possa colocar o problema de sua encarnação. O sentimento de continuidade torna-se residual aos locais. Há locais de memória porque não há mais meios de memória. ${ }^{3}$

No desejo de escrever a narrativa dos vencidos, os novos iconoclastas têm a necessidade de destruir o vencedor e como não é possível destruí-los na carne, a imagem encarna suas presenças. Horst Bredekamp, em seu livro Teoria do acto icónico ${ }^{4}$, identifica um fenômeno de substituição entre corpo e imagem que acontece frequentemente como fundamentação para explicar, dentre outras coisas, a destruição de imagens 
Na substituição, os corpos são tratados como imagens e as imagens como corpos. [...] A recíproca substituição de corpo por imagem encontra-se na origem de processos que vão desde a ilustração do sagrado e da natureza, passando pelo iconoclasmo, até as questões icônicas da política e do direito e, ainda, à guerra das imagens. Na sua vertente tanto produtiva quanto destrutiva, estes processos são mais atuais do que nunca. ${ }^{5}$

A face política da iconoclastia contemporânea aparece, então, como uma ação de reparação histórica. Ela nasce do desejo de resgatar memórias coletivas, reescrever a história a partir de outras narrativas e construir novos lugares de memória. Estátuas e monumentos se tornaram, deste modo, um novo "bezerro de ouro", e suas destruições almejam desconstruir ídolos do passado e iniciar uma nova aliança.

Se por um lado entendemos tal dimensão da iconoclastia contemporânea como um ato revolucionário de tendência decolonial, por outro testemunhamos a iconoclastia sendo utilizada cada vez mais como ferramenta de deslegitimação de ideologias e religiosidades minoritárias. Durante o processo eleitoral de 2018, por exemplo, fomos chocados pela destruição, cometida por dois então candidatos a deputados do PSL, de uma placa homenageando a deputada negra e defensora de pautas minoritárias Marielle Franco, que havia sido brutalmente assassinada no ano anterior. A placa em questão, foi utilizada por militantes de esquerda para cobrir uma das placas de identificação da praça, batizada em homenagem ao General Floriano Peixoto, que abriga a sede da Câmara Municipal do Rio de Janeiro. Segundo uma reportagem do Estadão ${ }^{6}$, os candidatos estariam combatendo uma suposta depredação pública cometida pelos militantes de esquerda e restaurando a homenagem ao general militar cujas ideologias seriam, naturalmente, mais alinhadas às suas próprias. O que testemunhamos, na verdade, foi uma reafirmação da tentativa de silenciamento de Marielle e de tudo que ela representa politicamente e socialmente. A placa, um objeto inanimado, deste modo, incorporou todos os princípios defendidos pela vereadora que colocavam em xeque a hegemonia da direita neofascista brasileira. Assim, a ameaça supostamente causada por tais princípios foi transferida para uma imagem que se tornou alvo de destruição. Este evento confirma o que David Freedberg reconhece como um medo da imagem que assola os censores e iconoclastas. Segundo David Freedberg,

5 Ibid., p. 131.

6 Candidatos do PSL destroem placa com homenagem a Marielle Franco. Estadão, Rio de Janeiro, 03 de out. de 2018. Disponível em <https://politica.estadao.com.br/noticias/eleicoes,candidatos-do-psI-destroem-placa-com-homenagem-a-marielle-franco,70002531740> Acesso em: 10 de set. de 2021. 
O uso de imagens em diferentes culturas e longos intervalos de tempo é conduzido por fatores psicológicos profundos que têm suas raízes em relações neurais específicas entre visão, movimento e incorporação. São relações especialmente críticas para a iconoclastia, visto que coincidem com muitos dos fundamentos dos medos que os atos iconoclastas demonstram: o medo de que a imagem morta se mova, que os olhos testemunhem os poderes realistas das imagens, que de alguma forma haja um corpo na imagem - mesmo que abstrato. ${ }^{7}$

Tal lógica de "incorporação" transparece de maneira ainda mais clara nos processos iconoclastas que tem como alvos imagens religiosas. Nestes casos, os iconoclastas operam ainda mais intensamente segundo o que Bredekamp conceitua como "ato icônico substitutivo" no qual uma imagem inanimada é tratada como um corpo vivo, ativo e potente. Desde o emblemático episódio conhecido como "chute na santa" no qual o pastor da Igreja Universal Sérgio von Helder atacou uma imagem de Nossa Senhora Aparecida em rede nacional no ano de 1995 até os recentes ataques a imagens de orixás e a templos de religiões afrobrasileiras, notamos que a iconoclastia motivada por intolerância religiosa vêm crescendo. Segundo uma reportagem do O Globo ${ }^{8}$, somente em 2018, trinta ataques a templos de religiosidades de matriz africana foram registrados na Baixada Fluminense. De acordo com Freedberg,

Repetidamente, censura e iconoclastia comprovam a ameaça que parece advir do pensamento de que há vida - um corpo vivo - em uma imagem feita de matéria morta. Sua habilidade de se tornar viva - ou de ser vivificada - parece inescapável. Subjacente a todos estes atos é o esforço para silenciar a imagem, para deixar claro que ela não está viva e não voltará a falar, ver ou agir. ${ }^{9}$

7 Tradução de Felipe da Silva Corrêa para o presente dossiê: "[...] Driving the use of images across cultures and long chronological spans are deep psychological factors that have their roots in specifiable neural relationships between vision, movement, and embodiment. They are relationships that are especially critical for iconoclasm, since they coincide with many grounds of the fears to which iconoclastic acts testify: that the dead image moves, that the eyes bear witness to the lifelike powers of the image, that there is somehow a body in that image - even an abstract one" (FREEDBERG, D. The Fear of Art: How Censorship Becomes Iconoclasm. Social Research: An International Quarterly, vol. 83 no. 1, 2016, p. 70.)

8 Terreiro de candomblé é depredado em Nova Iguaçu e religiosos são expulsos. G1, Rio de Janeiro, 29 de mar. de 2019. Disponível em <https://g1.globo.com/rj/rio-de-janeiro/noticia/2019/03/29/ terreiro-de-candomble-e-depredado-em-nova-iguacu-religiosos-foram-expulsos.ghtml> Acesso em: 26 de ago. de 2021.

9 Tradução de Felipe da Silva Corrêa para o presente dossiê: "Over and over again, censorship and iconoclasm testify to the threat that seems to be posed by the anomaly of thinking that life-a living body-exists in the image made of dead material. Its ability to come alive-or or be enlivenedseems inescapable. Underlying all these acts is the effort to silence the image, to make clear that it 
Nestes casos, o novo "bezerro de ouro" destruído representa o próprio corpo de uma alteridade desconhecida que amedronta e assim é alvo de um processo de deslegitimação como o ídolo mentiroso ou supersticioso ainda que, na verdade, em uma aparente contradição, acabe sendo empoderado.

Com efeito, este reforça o que recusa e rejeita: afirma que as imagens são inanimadas mas, ao aniquilá-las como se de criminosos, traidores ou hereges se tratassem, reconhece-lhes a vida, ainda que para logo de seguida a suprimir. Avaliado pelo grau da sua atividade perante a imagem, o iconoclasta revela estar mais influenciado por ela do que aquele que venera as imagens. ${ }^{10}$

Deste modo, a iconoclastia acaba, ironicamente, atestando o poder das imagens de expressões religiosas que lutam para sobreviver diante da intolerância e do racismo.

Concluímos, então, que é necessário entender a iconoclastia contemporânea não como uma ideologia em si, mas como uma ferramenta que pode ser utilizada pelas mais diferentes ideologias. Entendido tal caráter da iconoclastia contemporânea nos perguntamos: podemos considerar tais ações de destruição, motivadas pelas mais diversas ideologias, como sintomas de um novo surto iconoclasta? Acredito que o que temos testemunhado na contemporaneidade pode ser entendido como uma batalha de narrativas acompanhada por uma nova guerra das imagens na qual a iconoclastia, muitas vezes, é utilizada como arma. O momento presente, então, nos impele a pensar com urgência a questão da iconoclastia, tanto a partir de suas manifestações contemporâneas quanto a partir da sua dimensão histórica.

Apesar do estranhamento e da revolta seletiva diante de alguns atos iconoclastas contemporâneos por parte da opinião pública, sabemos que "derrubar estátuas" não é algo novo. A iconoclastia política contemporânea, inclusive, tem suas raízes diretas em questões surgidas no contexto Revolução Francesa, quando os revolucionários se viam no dilema entre destruir os símbolos do Antigo Regime e preservar seu patrimônio histórico, entre derrubar estátuas ou levá-las para os recém criados museus.

is not alive and will not speak, see or act again." (FREEDBERG, 2016, p. 76.)

10 BREDEKAMP, Op. Cit., p. 157 
Para além da Revolução Francesa, podemos buscar as origens da iconoclastia em um passado muito mais longínquo. Segundo David Freedberg, poderíamos, até mesmo, entender os palimpsestos das cavernas do paleolítico como os primeiros registros de ações iconoclastas ${ }^{11}$. De acordo com Freedberg, estas ações somente ocorreriam porque a imagem sempre exerceu um "poder" sobre a mente humana, que reage a ela de diferentes maneiras, inclusive através de sua destruição.

As pessoas são excitadas sexualmente por pinturas e esculturas; elas quebram pinturas e esculturas; as mutilam; as beijam, choram diante delas e seguem em jornadas até elas; são acalmadas por elas, agitadas por elas e incitadas à revolta. Elas agradecem por meio delas, esperam ser elevadas por elas e são levadas aos mais altos níveis de empatia e medo. As pessoas sempre responderam dessa maneira e ainda o fazem. ${ }^{12}$

No contexto da Antiguidade, ações iconoclastas de caráter político e religioso aconteceram no Egito durante os reinados de Hatshepsut e Akhenaton que tiveram seus governos deslegitimados e suas memórias apagadas. Na Grécia Antiga, testemunhamos a iconoclastia através das constantes destruições do Templo de Ártemis em Éfeso e no caso do complô político que motivou a destruição das estátuas de Hermes em Atenas no contexto da Guerra do Peloponeso. Identificamos também uma forte tradição iconoclasta em Roma, cujo hábito de destruição era tão presente que a iconoclastia foi tornada lei através dos processos da Damnatio Memoriae.

$\mathrm{Na}$ Idade Média, o Oriente viveu tensões durante dois surtos iconoclastas no Império Bizantino. Já no Ocidente, uma ação isolada de destruição levada a cabo por Serenus, bispo de Marselha, motivou a escrita de uma das mais famosas defesas da imagem através da carta-resposta do Papa Gregório Magno. Em termos de iconoclastia religiosa, a Europa da Idade Moderna também viveu um grande surto de destruição no contexto da Reforma Protestante no século XVI.

11 FREEDBERG, D. Iconoclasia. Historia y psicología de la violencia contra las imágenes. Buenos Aires: Sans Soleil Ediciones Argentina, 2017, p. 42.

12 FREEDBERG, D. The power of images. Study in the history and theory of response. Chicago e Londres: University of Chicago, 1991, p. 1. 
A era das guerras e revoluções também testemunhou ações de destruição motivadas por razões políticas desde a já citada Revolução Francesa, passando pelas Grandes Guerras até as constantes ações iconoclastas que marcaram todo o período da União Soviética.

Na contemporaneidade, temos assistido a destruições motivadas por princípios políticos, religiosos e ideológicos dos mais diversos. Assim, se por um lado reconhecemos o caráter decolonial de uma parcela dos atos iconoclastas contemporâneos como as destruições das estátuas de Colombo na América Latina, no outro extremo a iconoclastia também vem sendo frequentemente utilizada como instrumento de perseguição e racismo como pudemos ver em ações como a destruição da placa da vereadora Marielle.

Também observamos destruições ligadas a fatores financeiros, como as muitas estátuas roubadas para ter seu bronze fundido e comercializado como, por exemplo, o monumento a Marechal Deodoro da Fonseca no Rio de Janeiro que teve uma parte furtada na madrugada do dia 17 de fevereiro de 2020. Vemos até mesmo destruições acidentais como as constantes restaurações malsucedidas, dentre elas, a famosa interferência em um Ecce Homo por Dona Cecília na Cidade de Borja na Espanha e outras.

Deste modo, é premente entender a dimensão histórica da iconoclastia (e de outras estratégias de destruição) e seus impactos na contemporaneidade. O dossiê proposto, portanto, apresenta discussões em torno de ações, objetos, conceitos e tantas outras questões que podem ser relacionadas com processos de iconoclastia em suas mais diversas manifestações.

Abrimos nosso dossiê com a tradução do texto The Fear of Art: How Censorship Becomes Iconoclasm de David Freedberg. Neste trabalho, o autor investiga as razões psicológicas que levam a um medo da imagem que frequentemente estimula reações como a censura e a iconoclastia.

Em seguida, em seu artigo The Power of Images, Reconsidered, Erin Thompson coloca uma nova luz sob a canônica teoria do próprio David Freedberg para a explicar a iconoclastia. Thompson aponta que Freedberg, como especialista em iconoclastia protestante no século XVI, não consegue dar conta de todas as camadas do fenômeno iconoclasta contemporâneo. Segundo a autora, ao se mostrar mais interessado em analisar os aspectos psicológicos dos eventos iconoclastas, Freedberg acaba negligenciando questões legais e políticas envolvidas nos recentes atos de derrubada de monumentos públicos de caráter colonial e racista. Ao constatar que "[...] aqueles que retiraram monumentos em 2020 parecem ter tomado decisões deliberadas 
que respondem racionalmente aos monumentos, considerando as restrições legais e políticas", Thompson questiona a crença que julga Freedberg ter de que a "[...] iconoclastia e censura são sempre reações impensadas às imagens, disfarces repressivos para um medo irracional de que uma imagem possa realmente ganhar vida."

Ao delinear uma breve história da iconoclastia em seu texto Da iconoclastia à política das imagens: as aventuras da negatividade, Márcio Seligmann aborda questões fundamentais da sua própria trajetória de pesquisa como os horrores da guerra e o trauma, mas também se apoia em uma leitura revolucionária das teorias de Benjamin para mostrar um potencial construtivo presente em determinadas ações de destruição. Ao final de seu artigo, o autor aborda uma virada decolonial da cultura a partir da teoria de Ndikung e das obras artísticas de Jaime Lauriano, Rosana Paulino e Alfredo Jaar, cujas poéticas (a meu ver) podem ser consideradas iconoclastas em um sentido ampliado do termo, uma vez que elas buscam destruir as narrativas coloniais.

A iconoclastia é, como já observado, historicamente um dos modos de reagir diante do impacto que uma imagem exerce sobre a mente humana. Em seu artigo Contra imagens: apagamento, iconoclastia, devoração e demonização, Alberto Klein investiga a iconoclastia e outros métodos de insurgência diante das imagens. Para Ihe ajudar nesta empreitada, Klein toma emprestado do Cristianismo o conceito de "economia", explorado atualmente por pensadores como Mondzain e Belting, e o utiliza para refletir sobre os diversos modos de agenciamento da imagem (seja ela religiosa ou não) na contemporaneidade.

Seguindo uma abordagem histórica para analisar a iconoclastia religiosa, Débora Amaral, em seu artigo Iconoclastia e milagre: a Passio Imaginis na Península Ibérica (séculos XIII-XVII), mostra como a lenda bizantina da Passio Imaginis foi assimilada na Península Ibérica, onde repercutiu em outras lendas similares que foram utilizadas como argumento contra a iconoclastia. A lenda narra um episódio no qual um grupo de hebreus direcionou a um crucifixo os mesmos castigos que teriam sido direcionados ao próprio Cristo no passado. Diante da violência, a imagem teria reagido vertendo sangue e água. O grupo, então, teria oferecido os líquidos a enfermos que foram curados. Tal evento, assim, teria estimulado suas conversões para o Cristianismo. Em essência, a autora mostra como narrativas sobre imagens de Cristo que reagiam milagrosamente diante de ataques iconoclastas foram utilizadas em um contexto de oposição dos cristãos aos judeus, mouros e até mesmo conversos que ocupavam a Península Ibérica e foram personagens de desavenças religiosas principalmente no contexto das guerras da 
Reconquista.

Na sequência temos dois artigos que contribuem para uma reformulação do conceito de "vandalismo" e das noções pré concebidas subjacentes a ele. Dario Gamboni, em seu livro A Destruição da Arte $^{13}$, faz uma clássica diferenciação entre o que seria entendido como um ato iconoclasta e um ato de "vandalismo", considerando que a utilização dos dois termos passou por uma grande abertura semântica ao longo da História. Segundo o autor, a palavra "vandalismo", utilizada pela primeira vez por Henri Grégoire para definir a destruição de monumentos na França revolucionária, seria entendida, atualmente, como uma ação de destruição associada a condutas gratuitas, desprovidas de sentido ou de motivações ideológicas. Já o termo "iconoclastia", nascido no contexto religioso do Império Bizantino, seria utilizado, atualmente, para definir ações de destruição motivadas por ideologias ou crenças específicas, sejam elas de caráter religioso ou político.

Ao analisar as ações de destruição direcionadas a fonte Ramos Pinto, Rafael Cardoso em seu artigo Vandalismo ou iconoclastia? A fonte Ramos Pinto, no Rio de Janeiro contesta o entendimento usual do termo "vandalismo" e cunha a expressão "iconoclastia vulgar", ou seja, um ato de destruição anônimo, em primeira instância percebido como isento de motivações políticas ou religiosas, porém com forte caráter contestatório. Os ataques iconoclastas à fonte Ramos Pinto foram constantemente atribuídos pela imprensa aos "vândalos" moradores do Morro da Babilônia. Realizados em contextos de reformas urbanas que visavam, dentre outras coisas, a remoção de favelas, tais ações são vistas por Cardoso como uma reação intensificada por uma guerra cultural no qual os possíveis iconoclastas, os "moleques favelados", não se viam representados no monumento em questão. $O$ autor ainda chama atenção para um "vandalismo embelezador" perpetrado pelo poder público e pela especulação imobiliária, capaz de eliminar grandes obras e construções sem causar na opinião pública a mesma comoção gerada por pequenas ações de "vandalismo" realizadas por camadas menos favorecidas da sociedade.

O artigo de Gabriela da Fonseca, Não estão preocupados com as paredes... estão preocupados com a dor!": a revolta por Marielle e Anderson, também revisita o conceito de "vandalismo". Durante manifestações de repúdio e

13 GAMBONI, D. The destruction of art: Iconoclasm and Vandalism Since the French Revolution. Londres: Reaktion Books, 1997. 
dor diante do brutal assassinato político de Marielle e Anderson, "vândalos" marcaram as paredes do Palácio Pedro Ernesto, prédio que abriga a câmada dos vereadores do Rio de Janeiro, com mensagens de protesto. Tais manifestações iconoclastas agudizaram um velho conflito entre preservação do patrimônio histórico e luta pelos direitos de minorias que tem suas raízes históricas na crise iconoclasta desencadeada pelos processos da Revolução Francesa. Gabriela da Fonseca se mostra ciente de toda a dimensão histórica deste debate ao analisar as intervenções iconoclastas feitas pelos manifestantes no Palácio Pedro Ernesto e o debate que tais ações desencadearam nas redes sociais. A autora faz uma necessária revisão do conceito de "vândalo" e questiona as noções estratificadas de civilidade e barbárie, nos conduzindo a uma reflexão de caráter crítico e decolonial acerca de interferências tradicionalmente consideradas pela sociedade como atos bárbaros de depredação do patrimônio. Fonseca, deste modo, resgata a imagem do vândalo e lhe dá um status de revolucionário na importante batalha em busca de justiça social.

Os artigos de Cardoso e Fonseca se complementam no sentido de repensar o problemático conceito de "vandalismo" e colocar um novo olhar sobre a figura do vândalo, agora entendido como agente de contestação e criador de uma noção decolonial de civilidade.

Por fim, fechamos nosso dossiê com a contribuição artística de Denilson Baniwa através de um texto crítico sobre suas ações de projeção de imagens em edifícios e monumentos das grandes cidades contemporâneas, e através do seu poema "flashes in the sky of the memory". Segundo o próprio artista, o poema se relaciona profundamente com suas obras de projeção, como Petróglifos na Selva de Pedra e Me deixa Ser Selvagem. Em Petróglifos na Selva de Pedra (2018), Denilson usou edifícios de São Paulo como suporte para as imagens/histórias dos povos que vieram antes da cidade, antes de nós. Já Me deixa ser selvagem (2020), cujas fotografias da ação em Brasília nos foram cedidas pelo artista, se insere no contexto de uma campanha que visava pressionar líderes globais pelo fim do comércio de animais silvestres. Com estas obras, o artista cria lugares de memórias ancestrais em cima das selvas de pedras que soterraram evidências da cultura indígena, mostrando que essa cultura não morreu, que ela se mantém viva e ativa. Em uma atitude simbolicamente iconoclasta, Denilson faz uma arte permeada por uma importante crítica aos processos supostamente "civilizatórios" da colonização. 
Em meio a mais atual crise iconoclasta, na qual a destruição é utilizada como arma de batalha nas mãos das mais diversas ideologias, nos perguntamos quais ídolos queremos cultuar, quais alianças queremos estabelecer e quais lugares de memória queremos construir. Nos perguntamos quais "bezerros de ouro" devem ir para o chão e quais devem continuar de pé. Me arrisco a dizer que a destruição (seja ela material ou simbólica) de determinados ídolos do passado tem um potencial construtivo quando utilizada para contestar os horrores perpetrados por uma sociedade supostamente civilizada e assim escrever novas narrativas.

\section{Referências}

A Bíblia de Jerusalém. São Paulo: Paulus, 2019.

BREDEKAMP, H. Teoria do acto icónico (trad. A. Mourão). Lisboa: KKYM, 2015.

FREEDBERG, D. The power of images. Study in the history and theory of response. Chicago e Londres: University of Chicago, 1991.

FREEDBERG, D. The Fear of Art: How Censorship Becomes Iconoclasm. Social Research: An International Quarterly, vol. 83 no. 1, 2016.

FREEDBERG, D. Iconoclasia. Historia y psicología de la violencia contra las imágenes. Buenos Aires: Sans Soleil Ediciones Argentina, 2017.

GAMBONI, D. The destruction of art: Iconoclasm and Vandalism Since the French Revolution. Londres: Reaktion Books, 1997.

MBEMBE, A. O que fazer com as estátuas e os monumentos coloniais? Revista Rosa N. 2, 2020.

NORA, Pierre. Entre memória e história: a problemática dos lugares. Projeto História, São Paulo, n.10, dez. 1993. 